\title{
The complexity of the relationship between chronic pain and quality of life: a study of the general Norwegian population
}

\author{
Astrid K. Wahl • Tone Rustøen • Berit Rokne • \\ Anners Lerdal • Øistein Knudsen · Christine Miaskowski • \\ Torbjørn Moum
}

Accepted: 11 July 2009/Published online: 18 August 2009

(C) The Author(s) 2009. This article is published with open access at Springerlink.com

\begin{abstract}
Purpose The aims of this paper were to evaluate the relationship between chronic pain and global quality of life (GQOL) and to explore the effect of possible confounders, mediators, and moderators such as selected demographic variables, chronic illnesses, stress-related symptoms, fatigue, and subjective health of the relationship between chronic pain and GQOL.

Methods We used a cross-sectional design, including 1,893 respondents from a population of 4,000 of Norwegian citizens, aged 19-81 years, who were randomly drawn from the National Register by Statistics Norway in
\end{abstract}

\footnotetext{
A. K. Wahl (ه)

Institute of Nursing and Health Sciences, Medical Faculty, University of Oslo, Pb.1153 Blindern, 0316 Oslo, Norway

e-mail: a.k.wahl@medisin.uio.no

T. Rustøen · C. Miaskowski

Centre for Shared Decision Making and Nursing Research, Rikshospitalet-Radiumhospitalet, Oslo, Norway

B. Rokne

Department of Public Health and Primary Health Care, Medical Faculty, University of Bergen, Bergen, Norway
}

\author{
A. Lerdal \\ Department of Health Sciences, Buskerud University College, \\ Drammen, Norway \\ $\varnothing$. Knudsen \\ Directorate for Civil Protection and Emergency Planning, \\ Tonsberg, Norway \\ C. Miaskowski \\ School of Nursing, University of California, San Francisco, USA \\ T. Moum \\ Department of Behavioural Sciences in Medicine, Medical \\ Faculty, University of Oslo, Oslo, Norway
}

November 2000 (48.5\%). Pain duration of more than 3 months was categorized as having chronic pain. The Quality of Life Scale, the Fatigue Severity Scale, and the Posttraumatic Stress Scale were used as our main dependent and independent variables, respectively. A series of multiple regression analyses (GLM in SPSS) were applied using GQOL as the dependent variable, entering subsets of independent variables in a theoretically predefined sequence.

Results In the total model, there was no significant relationship between chronic pain and GQOL. The model explained $39 \%$ of the variance in GQOL. For direct effect sizes, stress-related symptoms were related most strongly to GQOL, followed by subjective health, fatigue, chronic illnesses, and selected demographic variables.

Conclusion These findings support the assumption of a complex and indirect relationship between chronic pain and GQOL.

Keywords Chronic pain - General population . Quality of life - Stress-related symptoms · Fatigue

\begin{tabular}{|c|c|}
\hline \multicolumn{2}{|c|}{ Abbreviations } \\
\hline DSM-IV & $\begin{array}{l}\text { Diagnostic and statistical manual of mental } \\
\text { disorders } 4 \text { th edition }\end{array}$ \\
\hline FSS & Fatigue Severity Scale \\
\hline GQOL & Global quality of life \\
\hline HRQOL & Health-related quality of life \\
\hline ICD-10 & $\begin{array}{l}\text { International classification of diseases and } \\
\text { related health problems 10th revision }\end{array}$ \\
\hline PTSD & Posttraumatic stress disorder \\
\hline PTSS-10 & The Posttraumatic Stress Scale \\
\hline QOL & Quality of life \\
\hline QOLS-N & The Quality Of Life Scale-Norwegian version \\
\hline
\end{tabular}




\section{Introduction}

Chronic pain is a major and rapidly growing health problem worldwide. Chronic pain is defined as pain lasting more than 3 or 6 months, and population-based studies suggest that chronic pain occurs in $11-30 \%$ of the general population [1-6]. Two recent population studies in Norway found prevalence rates of chronic pain of $24.4 \%$ [2] to $30 \%$ [6]. The condition pain is difficult to treat and its disabling effect may be substantial [7]. Patients with chronic pain use substantial amount of health care resources [8].

Chronic pain is recognized as a biopsychosocial phenomenon in which biological, psychological, and social factors interact dynamically with each other [7]. The biopsychosocial perspective on pain emphasizes the patient's interpretation of pain as the key to understanding his or her responses to pain. Chronic pain may be viewed as a stressor that exceeds routine coping capacities, which in turn may lead to disability and reduced Quality of Life (QOL) [9-12]. QOL may be understood as physical, social, and mental well-being [health-related quality of life (HRQOL)], and as the individual's satisfaction with life [i.e., global quality of life (GQOL)] [13]. In a recent study of the relevant domains of patient-reported outcomes from the perspective of people who experience chronic pain, functioning, and well-being were considered as important areas affected by the presence of symptoms and as appropriate targets of treatment [14].

Several studies that have evaluated different HRQOL issues in patients with chronic pain concluded that these patients report a variety of problems, including disability and poorer physical and mental health [2, 14-36]. Chronic pain is associated with symptoms such as emotional distress, anxiety, depression, fatigue, and sleep disturbances [31-36]. The co-occurrence of chronic pain and posttraumatic stress disorder (PTSD) has also been reported [37]. However, there is a dearth of research on GQOL, and the strength of the relationship between chronic pain and GQOL, in particular, when people with no chronic pain are included.

It is accepted that there is not a direct, one-to-one causal relationship between disease, symptoms, functional limitations, disability, and poor life satisfaction (GQOL) [13]. Common underlying causes (confounders) may contribute to noncausal, spurious associations between chronic pain and GQOL, and the mediating and moderating roles of the said variables are not well understood. Nonmedical factors such as sociodemographics, personality, psychosocial, and cultural factors seem to influence GQOL more than HRQOL, thus making the association between chronic pain and GQOL difficult to disentangle [13].
Chronic pain is demanding and difficult to treat and should be approached using multidisciplinary efforts, including QOL as an important outcome. Success in the assessment and treatment of chronic pain depends on knowledge of the complex relationship between chronic pain and QOL [38]. Although a number of studies have evaluated the negative effects of chronic pain on QOL in different pain populations, we have found no studies that examined the relationship between chronic pain and GQOL in the general population. Cross-sectional data from a study of the Norwegian general population in 2000-2001 that focused on evaluating QOL, health status, fatigue, hope, and pain allowed us to evaluate some of the causal issues pertaining to the relationship between chronic pain and GQOL. We explored the confounding, mediating, and moderating roles of sociodemographic variables, chronic illnesses, stress-related symptoms, fatigue, and subjective health perceptions in GQOL. The purposes of this study were to evaluate the degree to which chronic pain is directly or indirectly related to GQOL and to identify the mediators of these relationships, while controlling for possible confounders and moderators such as demographic characteristics, chronic illnesses, stress-related symptoms, fatigue, and subjective health.

\section{Methods and materials}

Sample and data collection procedures

A total of 4,000 Norwegian citizens, aged 19-81 years, were randomly drawn from the National Register by Statistics Norway. Of the 4,000 questionnaires mailed, 56 participants could not be contacted because of an unknown address or recent death, which left 3,944 eligible respondents. In November 2000, the participants were sent a questionnaire inviting them to participate in a study that focused on evaluating QOL, health status, fatigue, hope, and pain in the general Norwegian population. To improve the response rates, individuals who did not respond within 4 weeks received one written reminder.

A total of 1,912 questionnaires were returned after the two mailings, of which 1,893 provided usable information, giving an overall response rate of $48.5 \%(1,912 / 3,944)$. About $85 \%$ of the responses were returned before the second mailing. Using the demographic data obtained from the National Register by Statistics Norway, the responders and nonresponders were compared. Significantly, lower response rates were obtained from younger individuals, men, participants with less education, and those who were not married.

Most of the respondents were women (52\%), married $(58 \%)$, and worked for pay (71\%; Table 1$)$. The mean age 
of the respondents was 45.2 years $(\mathrm{SD}=16.0)$ with a range of 18-81 years. A total of $501(27 \%)$ of the participants reported having a chronic disease or long-term health problems.

A complete description of the pain characteristics of this sample was published previously [6]. Data were collected on pain prevalence, severity, causes, duration, location, and treatment. In brief, from the total sample of respondents, $536(28.3 \%)$ individuals reported that they generally were in pain, and $454(24.4 \%)$ met the criteria for chronic pain. Women, older individuals, persons with less education, and those who received a pension reported chronic pain more frequently [6].
Instruments and scoring procedures

The questionnaire sent to study participants obtained information about sociodemographic characteristics, chronic illnesses, QOL, fatigue, stress-related symptoms, hope, and pain. This paper presents the data on sociodemographic characteristics, pain, chronic illnesses, fatigue, stress-related symptoms, and GQOL.

\section{Sociodemographic characteristics}

The questionnaire obtained information on age, sex, marital status, education, coresidence, employment status and
Table 1 Characteristics of respondents $(N=1,893)$ and nonrespondents $(N=2,066)$ a The respondents could select more than one alternative

-, No information available

* $P<0.01$ for differences between respondents and nonrespondents (chi-square); ** $P<0.001$, significantly more nonrespondents in group compared with "married/ cohabitant" in logistic regression with "respondent" status as dependent variable; *** $P<0.001$ for differences between respondents and nonrespondents ( $t$-test)

\begin{tabular}{|c|c|c|c|c|}
\hline & \multicolumn{2}{|c|}{ Respondents } & \multicolumn{2}{|c|}{ Nonrespondents } \\
\hline & $N$ & $\%$ & $N$ & $\%$ \\
\hline \multicolumn{5}{|l|}{ Age groups (years) } \\
\hline $18-39$ & 782 & 41 & 929 & 45 \\
\hline $40-59$ & 719 & 38 & 679 & 33 \\
\hline $60-81$ & 392 & 21 & 458 & 22 \\
\hline \multicolumn{5}{|l|}{ Gender $^{\mathrm{a}}$} \\
\hline Male & 907 & 48 & 1,083 & 52 \\
\hline Female & 986 & 52 & 983 & 48 \\
\hline \multicolumn{5}{|l|}{ Level of education* } \\
\hline $7-10$ years & 362 & 19 & 538 & 26 \\
\hline $11-12$ years & 558 & 30 & 649 & 32 \\
\hline 13 years & 267 & 14 & 541 & 26 \\
\hline $14-16$ years & 381 & 20 & 267 & 13 \\
\hline 17 years or more & 325 & 17 & 71 & 3 \\
\hline \multicolumn{5}{|l|}{ Marital status $* * *$} \\
\hline Married/cohabitant** & 1,104 & 58 & 939 & 46 \\
\hline Single** & 538 & 28 & 766 & 37 \\
\hline Widow/widower** & 88 & 5 & 146 & 7 \\
\hline Divorced** & 123 & 7 & 173 & 8 \\
\hline Separated & 28 & 1 & 42 & 2 \\
\hline Missing responses & 12 & 1 & & \\
\hline \multicolumn{5}{|l|}{ Coresidence $^{\mathrm{a}}$} \\
\hline Living with spouse with/without children & 1,367 & 72 & - & - \\
\hline Living with children without spouse & 71 & 4 & - & - \\
\hline Living with siblings/or other family members & 79 & 4 & - & - \\
\hline Living alone & 302 & 16 & - & - \\
\hline Living with others & 68 & 4 & - & - \\
\hline Work $^{\mathrm{a}}$ & & & - & - \\
\hline Paying job & 1,353 & 71 & - & - \\
\hline Whole time at home & 95 & 5 & - & - \\
\hline Studying, military service & 132 & 7 & - & - \\
\hline Unemployed & 52 & 3 & - & - \\
\hline Disablement benefit or old-age pension & 433 & 23 & - & - \\
\hline Health condition & 501 & 27 & - & - \\
\hline Chronic illness (more than the last 6 months) & - & - & - & - \\
\hline
\end{tabular}


source of income. Statistics Norway supplied information about age, sex, marital status, and educational status also for the eligible respondents who did not return the questionnaire.

\section{Chronic illnesses}

Questions in this section ascertained whether or not the person suffered from chronic illness (yes or no), and the number of illnesses.

\section{Pain}

Participants were asked to respond to a screening question about whether or not they generally had pain (yes or no). If they answered yes to this screening question, they were asked to provide more detailed information on their pain including when the pain started (year, month, and day). For the purposes of this study, chronic pain was defined as pain of at least 3 months duration [39]. A more detailed description of the pain questions and the prevalence and characteristics of chronic pain in this sample were published previously [6].

\section{Stress-related symptoms}

The Posttraumatic Symptoms Scale-10 (PTSS-10) is a 10item self-report questionnaire that assesses the presence and intensity of stress-related symptoms during the previous 7 days [40-42]. As its name suggests, the PTSS-10 was developed as a tool for surveying symptoms within the posttraumatic stress spectrum, as outlined and defined by the DSM-IV and ICD-10. In this study, no specific traumatic events were evaluated, although the individual items are relevant for describing stress-related symptoms without reference to potentially traumatic events. The questionnaire addresses stress-related symptoms such as sleep problems, nightmares, tension in the body, irritation, depression, nervousness, fluctuations in mood, feelings of guilt, and fear. These symptoms are rated on a seven-point Likert scale that ranges from 1 (never/rare) to 7 (very often), giving a total score of 10 to 70 . The validity and reliability of the PTSS-10 are well established [43]. The Cronbach's alpha in this study was 0.88 .

\section{Fatigue}

The Fatigue Severity Scale (FSS) was used to measure fatigue [44]. This scale comprises nine items that measure the impact of disabling fatigue on daily functioning. It has been used in several different populations, including both general populations and those with specific chronic illnesses. The items are rated on a Likert scale that ranges from 1 (completely disagree) to 7 (completely agree), with a higher score indicating a higher level of fatigue. Several studies have documented satisfactory results with regard to psychometric properties in many countries including Norway [45]. The Cronbach's alpha in this study was 0.88 .

\section{Subjective health}

Subjective health was measured using one item from the 26-item World Health Organization Quality of Life instrument (the WHOQOL-BREF) [46]. The single item asked the individual to respond to the following question: How satisfied are you with your health? The respondent answered using a scale from 1 (very dissatisfied) to 5 (very satisfied). This scale has established validity and its reliability has been estimated in the Norwegian general population [47].

\section{GQOL}

The Norwegian version of the Quality of Life Scale (QOLS-N) was used to measure GQOL. This scale covers a wide range of factors that are important to an individual's life and is holistic in scope [48]. The questionnaire contains 16 items that require respondents to estimate their satisfaction with different life domains such as physical and material well-being, personal development, relationships with others, participation in social, community, and civic activities, and recreation. Level of satisfaction is reported on a seven-point scale from "not satisfied" to "very satisfied". A total score is created as the sum of all of the items and ranges from 16 to 112 . Higher scores indicate a better GQOL. The scale was translated into Norwegian and has well-established validity and reliability $[49,50]$. For the purposes of this study, one item that asked about satisfaction with health was removed from the overall GQOL scale because of a possible conceptual overlap (operational confounding) with the variable "subjective health," which was used as a separate construct in some of the multivariate analyses. The Cronbach's alpha in this study was 0.89 .

\section{Statistics}

Data were analyzed using SPSS for Windows (version 16.0). Descriptive analyses were performed to assess the demographic and clinical characteristics of the sample. To evaluate the relationship between chronic pain and GQOL, the roles of possible confounders, mediators, and moderators were explored using a series of multiple regression analysis (GLM in SPSS) in predefined steps (A-F) using GQOL as the dependent variable. The following variables were defined as independent in the separate steps according to the presumed causal ordering of the factors, starting with 
pain plus the most exogenous variables (putative confounders), and then adding possible mediators and moderators first sequentially and then as a complete set.

- Step A: age, sex, education, work, marital status, cohabitation (all defined as possible confounders) + chronic pain.

- Step B: age, sex, education, work, marital status, cohabitation, chronic illness (yes or no), number of chronic diseases (defined as possible confounders) + chronic pain.

- Step C: age, sex, education, work, marital status, cohabitation, chronic illness (yes or no), number of chronic diseases (defined as possible confounders) + stress-related symptoms (defined as a possible mediator) + chronic pain.

- Step D: as for Step C, but with fatigue as a possible mediator.

- Step E: as for step C, but with subjective health as a possible mediator.

- Step F: as for step C, but with stress-related symptoms + fatigue + subjective health as possible mediators.

At each step, the interaction effects between independent variables were tested one pair at a time, with main effects retained in the regression models.

\section{Results}

Relationship between chronic pain and GQOL

Results of the analyses that evaluated the relationship between chronic pain and GQOL, including possible confounders and moderators such as selected demographic characteristics, illness, stress symptoms, fatigue, and subjective health are shown in Table 2. All independent variables showed significant bivariate associations with GQOL.

In the model that evaluated the relationship between chronic pain and QOL controlling for demographic variables (Table 2, step A), all variables were significantly related to GQOL. GQOL increased with increasing age $(B=0.13, P<0.001)$. GQOL was lower in men $(B=$ $-2.16, P<0.001)$. Higher educational level was related to better GQOL ( $B=1.03, P<0.001)$, and living alone was related to poorer GQOL $(B=-1.90, P<0.05)$. GQOL was lower in pensioners $(B=-3.70, P<0.001)$ and in those who were unemployed $(B=-9.05, P<0.001)$, divorced $(B=-3.16, \quad P<0.01)$ or unmarried $(B=$ $-1.81, P<0.05)$ than in those who were married and working for pay. Finally, having chronic pain related significantly to reduced GQOL $(B=-4.78, P<0.001)$. The model (step A) explained $11 \%$ of the variance in GQOL, and the bivariate association between pain and GQOL decreased only slightly after controlling for demographic characteristics.

When the illness variables (chronic illness, number of illnesses) were entered into the model (Table 2, step B), the relationship between chronic pain and GQOL remained significant but declined from $B=-4.78(P<0.001)$ to $\mathrm{B}=-2.84(P<0.001)$.

In step $C$, stress-related symptoms were added to the variables analyzed in step B. Chronic pain was no longer significant, which suggests that the effect of chronic pain on GQOL was mediated to a large extent by stress-related symptoms.

When fatigue was entered instead of stress-related symptoms as a possible mediator of the effect of chronic pain on GQOL (Table 2, step D), chronic pain $(B=$ $-1.49, P<0.05$ ) was again significantly related to GQOL, albeit at a lower level, which suggests a less-pronounced mediating role of fatigue.

Finally, when subjective health was entered as a mediator, a strong direct effect appeared $(B=5.17, P<0.001)$, and chronic pain was no longer associated with GQOL. This finding suggests that subjective health was a very proximal cause of GQOL and, in effect, mediated all of the negative impact of chronic pain on GQOL in this population.

When evaluating the total model (all variables from steps A to E), no significant relationship was found between chronic pain and GQOL (Table 2, step F). All the putative mediators (stress-related symptoms, fatigue, and subjective health) showed highly significant, direct associations with GQOL. This indicates that "subjective health" was not the "main mediating nexus" between chronic pain and GQOL, but that all mediators contributed to GQOL.

In the full model, GQOL increased with age $(B=0.05$, $P<0.05)$. Men had lower levels of GQOL $(B=-4.06$, $P<0.001$ ), and higher educational level was related to better GQOL $(B=0.38, P<0.05)$. GQOL was lower in people who were unemployed $(B=-4.92, P<0.05)$, divorced $(B=-1.98, P<0.05)$, or unmarried $(B=$ $-1.35, P<0.05)$. Chronic illness $(B=1.48, P<0.05)$ was significantly related to poorer GQOL. The total model (step F) explained 39\% of the variance in GQOL. In terms of direct effect sizes, stress-related symptoms $(F=283.72)$ were most strongly related to GQOL, followed by subjective health $(F=78.59)$ and fatigue $(F=24.28)$.

A systematic search for statistical interactions between chronic pain and the other independent variables revealed two significant moderating effects. First, a significant interaction between chronic disease and chronic pain $(F=4.62, \quad P=0.032)$, indicating that the negative 


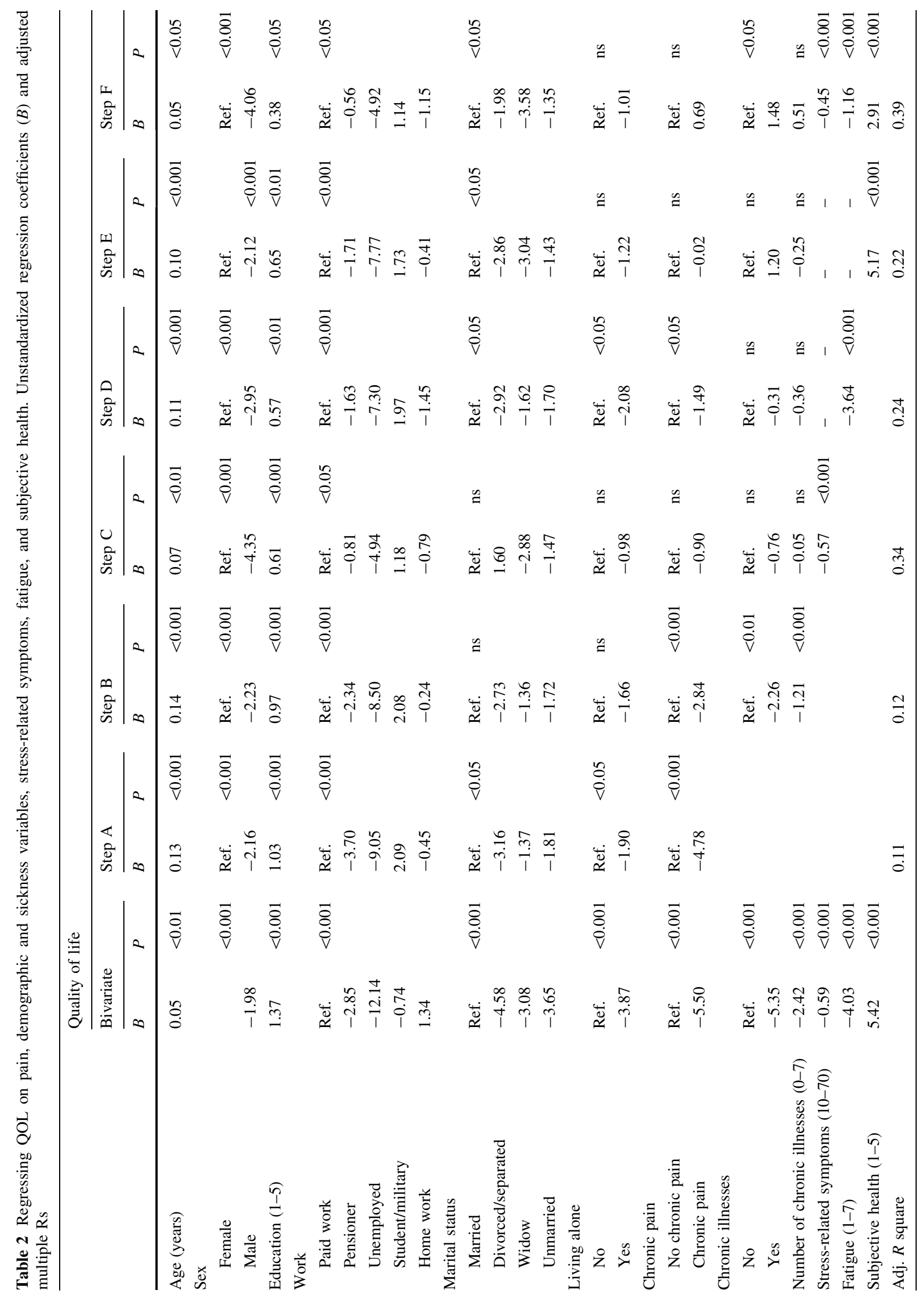


association between chronic pain and GQOL is particularly strong among persons who do not report having a chronic disease, i.e., among persons with a chronic disease, the "added burden" of chronic pain is not very strong. Second, there is an interaction between number of illnesses and chronic pain $(F=10.43, P=0.001)$, indicating that the negative association between GQOL and number of illnesses is much stronger among respondents with no chronic pain.

\section{Discussion}

In the present cross-sectional study, which includes data from a general population, we found no direct relationship between chronic pain and GQOL. Instead, we found that the relationship between chronic pain and GQOL is confounded and/or mediated by factors such as sociodemographic variables, chronic illnesses, stress-related symptoms, fatigue, and subjective health perceptions. The lack of a direct, oneto-one relationship between disease, symptoms, functional limitations, disability, and loss of satisfaction with life (GQOL) is well known [13]. Although our cross-sectional study could not establish or determine causality, our findings support the hypothesis that a complex relationship exists between chronic pain and GQOL. Chronic pain is not necessarily associated with poor GQOL [51]. For example, in a study of oncology outpatients, the most important predictors of GQOL were depression, social functioning, and physical functioning [52].

In the present study, stress-related symptoms were related most strongly to GQOL, and the relationship between chronic pain and GQOL became nonsignificant when stressrelated symptoms were introduced into the model. Most people with chronic pain experience emotional distress to varying degrees. Anxiety, depression, anger, frustration, and resentment are commonly reported by these patients [e.g., 30-33]. These negative emotions may be considered stressrelated symptoms that, in turn, may have a negative impact on GQOL. Patients with chronic pain tend to exhibit more PTSD symptoms [37]. For example, between 10 and $50 \%$ of patients who receive tertiary care treatment for chronic pain have symptoms that satisfy the diagnostic criteria for PTSD, compared to only $8 \%$ of the general population [53, 54].

Other stressors, which were not assessed in this study, may explain the relationship between stress-related symptoms and GQOL. To study stress-related symptoms using the PTSD-10 without knowing what stressor or possible trauma the respondents experienced may be considered as problematic. Epidemiologic studies have reported relatively high prevalence rates for a number of stressors that may be associated with PTSD [55-58]. For example, in a Norwegian epidemiologic study, $76 \%$ of 2,015 participants reported that they had experienced one or more of a list of 15 traumatic events based on a modification of the Diagnostic Interview Schedule [55, 56]. A population sample in Detroit reported a prevalence of $90 \%$ for any kind of severe trauma [57]. Additional research, particularly longitudinal studies, is needed to determine the impact of chronic pain, among other stressors, as a cause of stress-related symptoms in the general population and its relationship with GQOL.

This study found that fatigue and subjective health perceptions explained part of the variance in GQOL and that they mediated the relationship between chronic pain and GQOL. In a national health data survey on the impact of symptoms and impairments on overall health in the USA, pain and fatigue were reported among the most prevalent symptoms and were associated most strongly with overall health [59]. A better understanding of the relationship between pain and fatigue, their underlying mechanisms, and their changes with time would help to expand our knowledge about their relationship with GQOL.

The present study has some limitations. First, the chronic pain group was created based on self-reports of the participants rather than on diagnostic procedures. A second limitation is that the causal relationships between chronic pain and GQOL could not be examined because of the cross-sectional study design. Longitudinal studies are needed to evaluate the causal patterns and to develop theories about potential confounders or moderators of the relationship between chronic pain and GQOL. Characteristics of the individual (e.g., personality, motivation) and of the environment (e.g., social support, economic factors) also influence these associations. Because these factors were not assessed in this study, additional research that includes both personality and environmental factors is needed to understand more completely the complex relationships between chronic pain and GQOL. Third, we emphasize that the PTSS-10 was included as a tool to measure stress-related symptomology, a focal point of our study, and not as a tool for measuring the prevalence of PTSD or for identifying comorbidity of chronic pain and PTSD. Finally, differences in sociodemographic characteristics between the responders and nonresponders in this study may have influenced the relationships between the study variables, thus limiting the generalizability of the findings. The lower response rates in certain subgroups (young, men, unmarried people, and those with low educational level) are typical of broad population surveys like ours. This kind of nonrandom sample attrition probably distorts the point estimates (means, prevalence rates) for some of our main parameters (pain levels, stress). However, it seems likely that the relative size of the statistical associations, and the direct and indirect effects (our key issues) were robust to such typical lack of representativeness. 
Significant numbers of patients continue to experience chronic pain despite pharmacological interventions. People cope differently with stress, and this coping ability may contribute to QOL. Ample evidence suggests that the acceptance of pain is related to better well-being among patients with chronic nonmalignant pain. Acceptance of pain may be seen as a coping strategy and, consequently, one that reduces psychological distress, which in turn may impact on health perceptions and life satisfaction through mechanisms such as a response shift [27, 60-63].

\section{Conclusion}

Chronic pain may be less related to GQOL than the perception of health and stress. Although our cross-sectional study cannot confirm causality, our findings support the hypotheses of a complex relationship between chronic pain and GQOL. Additional research is needed to characterize more fully this relationship across the trajectory of the chronic pain experience. Future studies should use prospective designs, include a larger set of predictor variables, and employ more sophisticated statistical methods.

Open Access This article is distributed under the terms of the Creative Commons Attribution Noncommercial License which permits any noncommercial use, distribution, and reproduction in any medium, provided the original author(s) and source are credited.

\section{References}

1. Blyth, F. M., March, L. M., Brnabic, A. J., Jorm, L. R., Williamson, M., \& Cousins, M. J. (2001). Chronic pain in Australia: A prevalence study. Pain, 89(2-3), 12-134.

2. Breivik, H., Collett, B., Ventafridda, V., Cohen, R., \& Gallacher, D. (2006). Survey of chronic pain in Europe: Prevalence, impact on daily life, and treatment. European Journal of Pain, 10(4), 287-333.

3. Buskila, D., Abramov, G., Biton, A., \& Neumann, L. (2000). The prevalence of pain complaints in a general population in Israel and its implications for utilization of health services. The Journal of Rheumatology, 27(6), 1521-1525.

4. Catala, E., Reig, E., Artes, M., Aliaga, L., Lopez, J. S., \& Segu, J. L. (2002). Prevalence of pain in the Spanish population: Telephone survey in 5000 homes. European Journal of Pain, 6(2), 133-140.

5. Elliott, A. M., Smith, B. H., Penny, K. I., Smith, W. C., \& Chambers, W. A. (1999). The epidemiology of chronic pain in the community. Lancet, 354, 1248-1252.

6. Rustoen, T., Wahl, A. K., Hanestad, B. R., Lerdal, A., Paul, S., \& Miaskowski, C. (2004). Prevalence and characteristics of chronic pain in the general Norwegian population. European Journal of Pain, 8(6), 555-565.

7. Gatchel, R. J., Peng, Y. B., Peters, M. L., Fuchs, P. N., \& Turk, D. C. (2007). The biopsychosocial approach to chronic pain: Scientific advances and future directions. Psychological Bulletin, 133(4), 581-624.
8. Eriksen, J., Sjøgren, P., Ekholm, O., \& Rasmussen, N. K. (2004). Health care utilisation among individuals reporting long-term pain: An epidemiological study based on Danish National Health Surveys. European Journal of Pain, 8(6), 517-523.

9. Vlaeyen, J. W., \& Linton, S. J. (2000). Fear-avoidance and its consequences in chronic musculoskeletal pain: A state of the art. Pain, 85(3), 317-332.

10. Denison, E., Asenlöf, P., \& Lindberg, P. (2004). Self-efficacy, fear avoidance, and pain intensity as predictors of disability in subacute and chronic musculoskeletal pain patients in primary health care. Pain, 111(3), 245-252.

11. Stroud, M. W., Thorn, B. E., Jensen, M. P., \& Boothby, J. L. (2000). The relation between pain beliefs, negative thoughts, and psychosocial functioning in chronic pain patients. Pain, 84(2-3), 347-352.

12. Lamé, I. E., Peters, M. L., Vlaeyen, J. W., Kleef, M., \& Patijn, J. (2005). Quality of life in chronic pain is more associated with beliefs about pain, than with pain intensity. European Journal of Pain, 9(1), 15-24.

13. Wilson, I. B., \& Cleary, P. D. (1995). Linking clinical variables with health-related quality of life. A conceptual model of patient outcomes. JAMA, 273(1), 59-65.

14. Turk, D. C., Dworkin, R. H., Revicki, D., Harding, G., Burke, L. B., Cella, D., et al. (2008). Identifying important outcome domains for chronic pain clinical trials: An IMMPACT survey of people with pain. Pain, 137(2), 276-285.

15. Burckhardt, C. S., \& Jones, K. D. (2005). Effects of chronic widespread pain on the health status and quality of life of women after breast cancer surgery. Health and Quality of Life Outcomes, 28(3), 30

16. Arnold, L. M., Witzeman, K. A., Swank, M. L., McElroy, S. L., \& Keck, P. E., Jr. (2000). Health-related quality of life using the SF-36 in patients with bipolar disorder compared with patients with chronic back pain and the general population. Journal of Affective Disorders, 57(1-3), 235-239.

17. Khan, F., \& Pallant, J. (2007). Chronic pain in multiple sclerosis: Prevalence, characteristics, and impact on quality of life in an Australian community cohort. The Journal of Pain, 8(8), 614-623.

18. Kerr, S., Fairbrother, G., Crawford, M., Hogg, M., Fairbrother, D., \& Khor, K. E. (2004). Patient characteristics and quality of life among a sample of Australian chronic pain clinic attendees. Internal Medicine Journal, 34(7), 403-409.

19. Becker, N., Thomsen, A. B., Olsen, A. K., Sjøgren, P., Bech, P., \& Eriksen, J. (1997). Pain epidemiology and health related quality of life in chronic non-malignant pain patients referred to a Danish multidisciplinary pain center. Pain, 73(3), 393-400.

20. Bruce, J., \& Krukowski, Z. H. (2006). Quality of life and chronic pain four years after gastrointestinal surgery. Diseases of the Colon and Rectum, 49(9), 1362-1370.

21. Gerbershagen, H. J., Ozgür, E., Straub, K., Dagtekin, O., Gerbershagen, K., Petzke, F., et al. (2008). Prevalence, severity, and chronicity of pain and general health-related quality of life in patients with localized prostate cancer. European Journal of Pain, 12(3), 339-350.

22. Lynch, M. E., Campbell, F., Clark, A. J., Dunbar, M. J., Goldstein, D., Peng, P., et al. (2008). A systematic review of the effect of waiting for treatment for chronic pain. Pain, 136(1-2), 97-116.

23. Poobalan, A. S., Bruce, J., Smith, W. C., King, P. M., Krukowski, Z. H., \& Chambers, W. A. (2003). A review of chronic pain after inguinal herniorrhaphy. The Clinical Journal of Pain, 19(1), 48-54.

24. Boersma, K., \& Linton, S. J. (2006). Psychological processes underlying the development of a chronic pain problem: A prospective study of the relationship between profiles of psychological variables in the fear-avoidance model and disability. The Clinical Journal of Pain, 22(2), 160-166. 
25. Dersh, J., Gatchel, R. J., Mayer, T., Polatin, P., \& Temple, O. R. (2006). Prevalence of psychiatric disorders in patients with chronic disabling occupational spinal disorders. Spine, 31(10), $1156-1162$.

26. Jensen, M. P., Turner, J. A., \& Romano, J. M. (2001). Changes in beliefs, catastrophizing, and coping are associated with improvement in multidisciplinary pain treatment. Journal of Consulting and Clinical Psychology, 69(4), 655-662.

27. McCracken, L. M., Carson, J. W., Eccleston, C., \& Keefe, F. J. (2004). Acceptance and change in the context of chronic pain. Pain, 109(1-2), 4-7.

28. Turk, D. C., Robinson, J. P., \& Burwinkle, T. (2004). Prevalence of fear of pain and activity in patients with fibromyalgia syndrome. The Journal of Pain, 5(9), 483-490.

29. Turner, J. A., Franklin, G., \& Turk, D. C. (2000). Predictors of chronic disability in injured workers: A systematic literature synthesis. American Journal of Industrial Medicine, 38(6), 707-722.

30. Fredheim, O. M., Kaasa, S., Fayers, P., Saltnes, T., Jordhøy, M., \& Borchgrevink, P. C. (2008). Chronic non-malignant pain patients report as poor health-related quality of life as palliative cancer patients. Acta Anaesthesiologica Scandinavica, 52(1), 143-148.

31. Arvidsson, S., Arvidsson, B., Fridlund, B., \& Bergman, S. (2008). Health predicting factors in a general population over an eightyear period in subjects with and without chronic musculoskeletal pain. Health and Quality of Life Outcomes, 11(6), 98.

32. Keele, P., Creed, F., Tomenson, B., Todd, C., Borglin, G., \& Dickens, C. (2008). Psychosocial predictors of health-related quality of life and health service utilisation in people with chronic low back pain. Pain, 135(1-2), 142-150.

33. Jenewein, J., Moergeli, H., Wittmann, L., Büchi, S., Kraemer, B., \& Schnyder, U. (2009). Development of chronic pain following severe accidental injury. Results of a 3-year follow-up study. Journal of Psychosomatic Research, 66(2), 119-126.

34. Roth, R. S., Geisser, M. E., \& Bates, R. (2008). The relation of posttraumatic stress symptoms to depression and pain in patients with accident-related chronic pain. The Journal of Pain, 9(7), 588-596.

35. Elliott, T. E., Renier, C. M., \& Palcher, J. A. (2003). Chronic pain, depression, and quality of life: Correlations and predictive value of the SF-36. Pain Medicine, 4(4), 331-339.

36. Jensen, M. K., Thomsen, A. B., \& Højsted, J. (2006). 10-year follow-up of chronic non-malignant pain patients: Opioid use, health related quality of life and health care utilization. European Journal of Pain, 10(5), 423-433.

37. Sharp, T. J., \& Harvey, A. G. (2001). Chronic pain and posttraumatic stress disorder: Mutual maintenance? Clinical Psychology Review, 21(6), 857-877.

38. Lang, E., Liebig, K., Kastner, S., Neundörfer, B., \& Heuschmann, P. (2003). Multidisciplinary rehabilitation versus usual care for chronic low back pain in the community: Effects on quality of life. The Spine Journal, 3(4), 270-276.

39. Bonica, J. J., \& Loeser, J. D. (2001). Bonica's Management of Pain (3rd edition ed.). Philadelphia, PA: Lippincott Williams and Wilkins.

40. Eid, J., Thayer, J. F., \& Johnsen, B. H. (1999). Measuring posttraumatic stress: A psychometric evaluation of symptom- and coping questionnaires based on a Norwegian sample. Scandinavian Journal of Psychology, 40(2), 101-108.

41. Ersland, S., Weisaeth, L., \& Sund, A. (1989). The stress upon rescuers involved in an oil rig disaster. "Alexander L. Kielland" 1980. Acta Psychiatrica Scandinavica Supplementum, 355(3), 8-49.

42. Sund, A., Holen, A., \& Weisæth, L. (1983). Alexander L. Kiellandkatastrofen 27. mars 1980: psykiske reaksjoner hos overlevende : forelopig sluttrapport. Oslo: Kontoret for katastrofepsykiatri.

43. Weisaeth, L. (1989). The stressors and the post-traumatic stress syndrome after an industrial disaster. Acta Psychiatrica Scandinavica Supplementum, 355, 25-37.
44. Krupp, L. B., LaRocca, N. G., Muir-Nash, J., \& Steinberg, A. D. (1989). The fatigue severity scale. Application to patients with multiple sclerosis and systemic lupus erythematosus. Archives of Neurology, 46(10), 1121-1123.

45. Lerdal, A., Wahl, A., Rustoen, T., Hanestad, B. R., \& Moum, T. (2005). Fatigue in the general population: A translation and test of the psychometric properties of the Norwegian version of the Fatigue Severity Scale. Scandinavian Journal of Public Health, 33(2), 123-130.

46. Skevington, S. M., Lotfy, M., O'Connell, K. A., \& Group, W. H. O. Q. O. L. (2004). The World Health Organization's WHOQOLBREF quality of life assessment: Psychometric properties and results of the international field trial. A report from the WHOQOL group. Quality of Life Research, 13(2), 299-310.

47. Hanestad, B. R., Rustøen, T., Knudsen, O., Jr, Lerdal, A., \& Wahl, A. K. (2004). Psychometric properties of the WHOQOLBREF questionnaire for the Norwegian general population. Journal of Nursing Measurement, 12(2), 147-159.

48. Burckhardt, C. S., \& Anderson, K. L. (2003). The quality of life scale (QOLS): Reliability, validity, and utilization. Health and Quality of Life Outcomes, 1(1), 60.

49. Wahl, A., Burckhardt, C., Wiklund, I., \& Hanestad, B. R. (1998). The Norwegian version of the Quality of Life Scale (QOLS-N). A validation and reliability study in patients suffering from psoriasis. Scandinavian Journal of Caring Sciences, 12(4), 215-222.

50. Wahl, A. K., Rustoen, T., Hanestad, B. R., Lerdal, A., \& Moum, T. (2004). Quality of life in the general Norwegian population, measured by the Quality of Life Scale (QOLS-N). Quality of Life Research, 13(5), 1001-1009.

51. Niv, D., \& Kreitler, S. (2001). Pain and quality of life. Pain Practice, 1(2), 150-161.

52. Rustoen, T., Moum, T., Padilla, G., Paul, S., \& Miaskowski, C. (2005). Predictors of quality of life in oncology outpatients with pain from bone metastasis. Journal of Pain and Symptom Management, 30(3), 234-242.

53. Hickling, E. J., Blanchard, E. B., Silverman, D. J., \& Schwarz, S. P. (1992). Motor vehicle accidents, headaches and post-traumatic stress disorder: Assessment findings in a consecutive series. Headache, 32(3), 147-151.

54. Taylor, S., \& Koch, W. J. (1995). Anxiety disorders due to motor vehicle accidents: Nature and treatment. Clinical Psychology Review, 15(8), 721-738.

55. Ingebretsen, G., Sandanger, I., Sørensen, T., \& Dalgard, O. S (1995). Når ulykken rammer. Posttraumatisk stressforstyrrelse i Norge, forekomst og relasjon til sosialt nettverk. I Dalgard OS (Ed.), Sosialt nettverk, helse og samfunn. En teoretisk og praktisk tilnarming. Oslo: Gyldendal.

56. Sandanger, I., Nygard, J. F., Ingebretsen, G., Sorensen, T., \& Dalgard, O. S. (1999). Prevalence, incidence and age of onset of psychiatric disorders in Norway. Social Psychiatry and Psychiatric Epidemiology, 34(11), 570-579.

57. Breslau, N., Kessler, R. C., Chilcoat, H. D., Schultz, L. R., Davis, G. C., \& Andreski, P. (1998). Trauma and posttraumatic stress disorder in the community: The 1996 detroit area survey of trauma. Archives of General Psychiatry, 55(7), 626-632.

58. Kang, H. K., Natelson, B. H., Mahan, C. M., Lee, K. Y., \& Murphy, F. M. (2003). Post-traumatic stress disorder and chronic fatigue syndrome-like illness among Gulf War veterans: A population-based survey of 30, 000 veterans. American Journal of Epidemiology, 157(2), 141-148.

59. Stewart, S. T., Woodward, R. M., Rosen, A. B., \& Cutler, D. M. (2008). The impact of symptoms and impairments on overall health in US national health data. Medical Care, 46(9), 954962.

60. Vowles, K. E., \& McCracken, L. M. (2008). Acceptance and values-based action in chronic pain: A study of treatment 
effectiveness and process. Journal of Consulting and Clinical Psychology, 76(3), 397-407.

61. McCracken, L. M., \& Keogh, E. (2009). Acceptance, mindfulness, and values-based action may counteract fear and avoidance of emotions in chronic pain: An analysis of anxiety sensitivity. The Journal of Pain, 10(4), 408-415.

62. Vowles, K. E., McCracken, L. M., \& Eccleston, C. (2008). Patient functioning and catastrophizing in chronic pain: The mediating effects of acceptance. Health Psychology, 27(2 Suppl), S136-S143.

63. McCracken, L. M., \& Vowles, K. E. (2008). A prospective analysis of acceptance of pain and values-based action in patients with chronic pain. Health Psychology, 27(2), 215-220. 